http://dx.doi.org/10.35381/r.k.v5i4.950

\title{
Efectos económicos en el sector empresarial del Ecuador por las reformas tributarias en el ICE
}

\section{Economic effects in the business sector of Ecuador by the tax reforms in the ICE}

\author{
Jessica Alexandra Allauca-Llamuca \\ jessica.allauca02@est.ucacue.edu.ec \\ Universidad Católica de Cuenca, Cuenca \\ Ecuador \\ https://orcid.org/0000-0002-7524-0485 \\ Rolando Patricio Andrade-Amoroso \\ randradea@ucacue.edu.ec \\ Universidad Católica de Cuenca, Cuenca \\ Ecuador \\ https://orcid.org/0000-0002-6078-3487 \\ Pedro Yamil Astudillo-Arias \\ pastudillo@ucacue.edu.ec \\ Universidad Católica de Cuenca, Cuenca \\ Ecuador \\ https://orcid.org/0000-0003-4639-0318
}

Recibido: 01 de junio de 2020

Revisado: 20 de junio de 2020 Aprobado: 02 de septiembre de 2020 Publicado: 24 de septiembre de 2020 


\title{
RESUMEN
}

La investigación tuvo por objetivo analizar los efectos económicos en el sector empresarial del Ecuador por las reformas tributarias en el ICE del Ecuador. de tipo no experimental debido a que no se manipuló las variables de estudio, tuvo un alcance descriptivo. El $83 \%$ de los encuestados afirman que las reformas tributarias propuestas en el año 2019 han elevado de forma significativa sus precios de venta al público, en tanto que, el $17 \%$ señalan no haber tenido mayor afectación en sus precios de venta. Se proponen una serie de estrategias que los empresarios pueden adoptar con la finalidad de optimizar su pago de impuestos y cumplir a tiempo con sus obligaciones tributarias, las mismas se amparan en la determinación anticipada de los impuestos a efectos de la aprobación de la nueva ley tributaria en el Ecuador.

Descriptores: Presupuesto del Estado; tributación; política fiscal; hacienda pública. (Palabras tomadas del tesauro UNESCO).

\begin{abstract}
The objective of the research was to analyze the economic effects on the business sector of Ecuador due to the tax reforms in the ICE of Ecuador. of non-experimental type due to the fact that the study variables were not manipulated, it had a descriptive scope. $83 \%$ of those surveyed affirm that the tax reforms proposed in 2019 have significantly raised their sales prices to the public, while $17 \%$ indicate that they have not had a major impact on their sales prices. A series of strategies are proposed that entrepreneurs can adopt in order to optimize their payment of taxes and comply with their tax obligations on time, they are protected in the advance determination of taxes for the purposes of the approval of the new tax law in Ecuador.
\end{abstract}

Descriptors: State budget; taxation; fiscal policy; Public finance. (Words taken from the UNESCO thesaurus). 


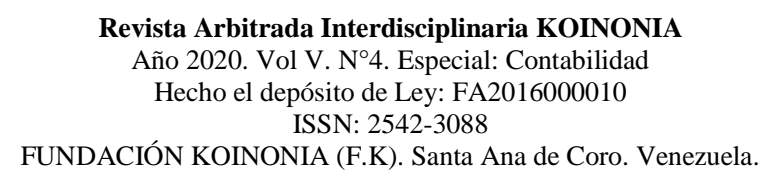

Jessica Alexandra Allauca-Llamuca; Rolando Patricio Andrade-Amoroso; Pedro Yamil Astudillo-Arias

\section{INTRODUCCIÓN}

En Ecuador el impuesto a los consumos especiales (ICE) es un tipo de tributo directoselectivo, que se graba a ciertos bienes nacionales e importados y de servicios en el momento que se realice la actividad, así también, la base imponible en el ICE está establecida en la Ley de Régimen Tributario, se graba considerando el precio ex fábrica. En este punto cabe mencionar que el término ex fábrica es cuando el vendedor entrega y deja las mercaderías a disposición del comprador, mientras que, el precio ex aduana es aquel que se obtiene de la suma de las tasas arancelarias, fondos y tasas extraordinarias. Es importante mencionar que con base en la recaudación tributaria el ingreso público se destina para cubrir los gastos originales generados por el país, los mismos que se encuentran definidos en el presupuesto general del Estado (PGE).

Por consiguiente, los ingresos del Estado están compuestos por ingresos permanentes, no permanentes y de financiamiento; los ingresos permanentes son aquellos que se reciben de forma continua como: impuesto al valor agregado (IVA), tributo a consumos especiales (ICE), tasas, donaciones corrientes y contribuciones, rentas de inversiones y multas, venta de bienes y servicios, entre otros; los ingresos no permanentes se reciben de manera temporal por alguna situación específica, así como, la trasferencia de donaciones de capital e inversión, es importante mencionar que los ingresos de financiamiento son aquellos percibidos por financiamiento público, ventas anticipadas, saldos disponibles, cuentas por cobrar y recuperación de inversiones.

El sistema tributario por medio de la recaudación normaliza la relación entre el Estado y los contribuyentes mediante los principios de progresividad, eficiencia, generalidad, simplicidad administrativa, transparencia, equidad y suficiencia recaudadora, es por esta razón, que el Estado promueve y estimula la obligación tributaria a través del Servicio de Rentas Internas (SRI) y otras entidades públicas que tienen como función la recaudación de los impuestos, en el Ecuador el $76 \%$ de la recaudación tributaria proviene de la renta y del IVA, por cuanto el primer tributo debe ser cancelado de forma anual y obligatoria por todas las personas naturales y jurídicas que conforman la economía del país 
(Asamblea Nacional República del Ecuador, 2019).

\section{Referencial teórico}

\section{Medidas tendientes a combatir la evasión y elusión fiscal en Ecuador}

En esta investigación se analiza de forma breve el proceso de facturación electrónica de los comprobantes de venta y su incidencia en la evasión tributaria, que provoca que el contribuyente declare y pague menos impuestos al incluir en sus declaraciones facturas de gastos no efectuadas, perjudicando así al Estado, quien recibe menos ingresos por recaudaciones fiscales y en consecuencia debe implementar mayores controles que se traducen en más gastos de recursos públicos.

Se incluye, además, el análisis de las reformas tributarias vigentes en el Ecuador a partir del año 2020 relacionadas con el impuesto a los consumos especiales (ICE), incluido los mecanismos que el Servicio de Rentas Internas ha establecido para evitar la evasión fiscal o defraudación considerada como un delito. En este contexto, la administración tributaria debe combatir el problema de evasión utilizando ciertas herramientas de control sobre los contribuyentes como es la facturación electrónica, sin embargo, hay que preguntarse si $i$ es posible que estos instrumentos se conviertan a la vez en caminos hacia el fraude fiscal? La evasión es un problema que hoy en día se registra en todos los países, durante los últimos años, de forma principal a través del uso de comprobantes de venta, este proceso es cada vez más sofisticado y, por consiguiente, difícil de detectar en gran medida por los acelerados cambios tecnológicos.

Otro mecanismo de control, se da mediante la valoración de indicadores en el ámbito fiscal de un país, los mismos que miden la presión impositiva, que corresponde al valor de los impuestos extraídos en función del volumen de producción en una economía, los mismos que constan en el PGE (Huerta-González, 2015). Partiendo de la definición del PGE, se considera al mismo como el instrumento que permite determinar y gestionar los ingresos y egresos de las entidades públicas que conforman las distintas funciones del Estado (no se consideran parte del PGE, los ingresos y egresos pertenecientes a la 


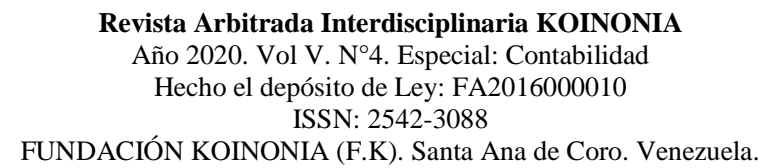

Jessica Alexandra Allauca-Llamuca; Rolando Patricio Andrade-Amoroso; Pedro Yamil Astudillo-Arias

seguridad social, la banca pública, las empresas públicas y los gobiernos autónomos descentralizados). En lo que corresponde a la fase de programación y formulación se incluyen los ingresos y egresos permanentes y no permanentes, de esta forma se garantiza el cumplimiento de las disposiciones de la Constitución de la República del Ecuador en lo concerniente al cumplimiento de la regla fiscal y financiamiento del presupuesto público.

Los egresos permanentes para salud, educación y justicia serán prioritarios y de manera excepcional, podrán ser financiados con ingresos no permanentes (Asamblea Nacional del Ecuador, 2008). Al respecto, el Servicio de Rentas Internas con la finalidad de generar transparencia en su accionar se ha acogido a las buenas prácticas recomendadas a nivel mundial, para ello, expone una serie de estrategias que promueven el cumplimiento voluntario de las obligaciones tributarias y la reducción del fraude fiscal. Entre las acciones destacadas por parte del organismo del control se encuentra el fortalecimiento del modelo institucional de gestión de riesgos que involucra la identificación, priorización, tratamiento y evaluación sistemática de los riesgos de incumplimiento de las obligaciones tributarias mediante el entendimiento de los impuestos.

La innovación a través de la implementación en la plataforma de análisis del comportamiento tributario, dentro de la cual se consideran los mapas de brechas tributarias, los modelos predictivos que son resultado de la aplicación de técnicas de minería de datos e inteligencia de información, que permiten hacer más eficiente el análisis, la prevención y focalización de las acciones del SRI; y, la transparencia institucional con la publicación de los resultados en acciones de control, acciones judiciales y de cobro, así como la información tributaria de grandes contribuyentes, grupos económicos y contribuyentes especiales (Llivicura-Ávila, 2019). 


\section{Estrategias tributarias para la recaudación de impuestos frente a la cultura tributaria del contribuyente}

Las estrategias tributarias son consideradas como un grupo de acciones para la recaudación óptima de los impuestos nacionales que se realizan a través del sistema en línea emitida por el Servicio de Rentas Internas, además, son importantes porque permite el cumplimiento de la misión, visión y objetivos planteados a largo plazo por el Estado, a su vez, identifican las posibles causas de evasión e infracción que cada año va en incremento (Ministerio de Economía y Finanzas, 2019). Cabe señalar que las estrategias tributarias atraen a los contribuyentes de una manera ética, legal y de fiel cumplimiento con el Estado, por tanto, es fundamental identificar el orden tributario de un país que permite pagar de manera justa los impuestos, optimizar los recursos internos y contribuir a la nación de una manera correcta a través de la legalidad en ordenanza y normativas prescritas en beneficio colectivo para toda la ciudadanía.

En Ecuador las estrategias tributarias son las principales alternativas para la eliminación del fraude fiscal, a través de acciones planificadas sistemáticas, en relación con la publicidad que motiva a los contribuyentes en una manera sana, el cumplimiento hacia el pago y la gestión a través del incentivo tributario, por cuanto, el ICE, así como otros impuestos representan en su mayoría el ingreso más relevante del presupuesto anual. Según (Zavala, 2015) el ICE se destina a los ingresos públicos por parte del Estado, estos son utilizados para satisfacer las necesidades de servicios de la población o invertir estos recursos en obras que de igual forma satisfacen a los sectores sociales, de esta manera se logra una distribución equitativa de los ingresos percibidos por el Estado, con el propósito de incrementar los beneficios para el país.

Sin embargo, a pesar de los esfuerzos del gobierno y la administración tributaria para incrementar la recaudación fiscal, existe un alto índice de evasión tributaria del ICE, siendo de carácter administrativo es una infracción penal incurrida por el contribuyente, donde se establece en forma clara la conducta por el tipo de evasión y elusión infringida. Al respecto, la evasión fiscal se da a través de una acción u omisión parcial o total que 


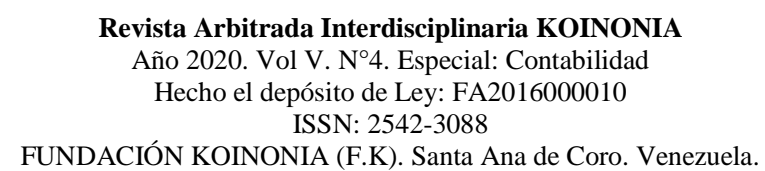

Jessica Alexandra Allauca-Llamuca; Rolando Patricio Andrade-Amoroso; Pedro Yamil Astudillo-Arias

tiende a reducir o retardar el cumplimiento de la obligación tributaria, entre sus características se presentan las siguientes:

1. Existe evasión no solo cuando se evita el pago del tributo en su totalidad, sino también cuando existe una disminución en el monto debido.

2. Debe estar referida a un determinado país cuyas leyes tributarias se han transgredido.

3. Se origina solo por parte de quienes están obligados a cancelar un impuesto al fisco, no hay evasión de aquellos que reciben un peso económico sin tener la obligación jurídica de pagarlo (Sánchez, et al., 2020).

Por su parte, (Santiana-Castillo, 2013) menciona que la elusión fiscal es aquella figura que consiste en evitar por medios lícitos, el pago de ciertos impuestos que aparentemente se debería abonar, esta situación se produce como consecuencia de deficiencias en la redacción de la ley, ya que sus autores no han tenido el cuidado de analizar y reformar el resto de normas tributarias. La elusión es también un acto de omisión realizado previo a la verificación del hecho generador, su finalidad es minimizar o evitar el pago de impuestos, lo cual constituye una forma de planificación fiscal agresiva, en la que se aprovecha los vacíos legales. En el Ecuador por evasión tributaria, el Estado pierde entre $\$ 300$ y $\$ 400$ millones anuales, esto se debe a que la imposición de impuestos parte de un principio que ha generado resistencia especialmente entre las clases más pudientes del país, donde se ha considerado que el sujeto pasivo que más tiene es quien más debe pagar impuestos (El Telégrafo, 2020).

Retomando el tema, la evasión a los consumos especiales en el marco jurídico consiste en no pagar el rubro fijado por la administración tributaria, provocando fraude a la ley. En este contexto, (Almeida-Haro, 2017) menciona varios métodos para la evasión tributaria; tales como: disminución de la base imponible que consiste en reducir el importe sobre el que se calcula el impuesto, lo que permitirá al evasor pagar menos. Otro método de evasión es la deducción de impuesto, aquí se suele aprovechar algunas estrategias para 


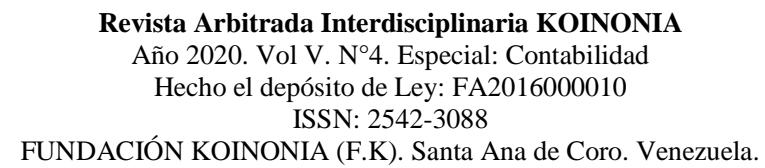

Jessica Alexandra Allauca-Llamuca; Rolando Patricio Andrade-Amoroso; Pedro Yamil Astudillo-Arias

obtener ciertas ventajas ofrecidas por la ley en materia impositiva, es decir, por ejemplo, utilizar gastos deducibles en una medida excesiva y sin respaldo legal.

Según (Illescas-Guillén, et al., 2020) manifiestan que el Estado tiene varias brechas en el proceso tributario y normativo, es así que, los contribuyentes encuentran varios vacíos legales para evadir impuestos, afectando la económica destinada al beneficio del país, siendo este uno de los problemas más graves que no solo afecta al ente recaudador, sino también, a todos los ecuatorianos, por cuanto el PGE no cubre con todos los gastos contraídos, puesto que a menor recaudación el presupuesto también tiende a disminuir. En este sentido, la evasión tributaria es uno de los problemas más relevantes a solucionar en el país, para ello, (Saeteros-Molina, et al., 2020) consideran que se requiere de una verdadera cultura tributaria a nivel individual y colectivo por parte de los contribuyentes, en definitiva, esto depende de una buena administración, de un gobierno dispuesto a modificar la percepción e imparcialidad en la recaudación tributaria.

En consecuencia, la cultura tributaria es una percepción social en medida del cumplimiento de las obligaciones tributarias en forma responsable a través de la confianza, ética personal y el respeto a la ley que promueve el Estado para la ejecución presupuestaria planificada en beneficio de la ciudadanía, cabe destacar que la administración de manera continua motiva la actitud responsable de los contribuyentes; al respecto, (Andrade-Donoso \& Cevallos-Caza, 2020) señala que el Estado debe fomentar valores éticos de cultura tributaria, por medio de la información real y verídica a todos los contribuyentes interesados.

\section{El impuesto a los consumos especiales (ICE) en Ecuador}

El ICE tiene su origen en el año 1893, a partir de su creación según (Mantilla-Falcón, 2017), este impuesto selectivo ha tomado importancia en el sistema impositivo del Estado, de tal manera que, se ha establecido una normativa que permite a los contribuyentes el cumplimiento de derechos y obligaciones fijados por los organismos encargados de su administración para mantener un control eficaz y oportuno que aporte 


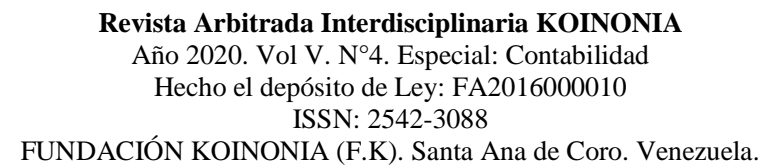

Jessica Alexandra Allauca-Llamuca; Rolando Patricio Andrade-Amoroso; Pedro Yamil Astudillo-Arias

al crecimiento económico del país.

Los bienes y servicios que gravan este impuesto según la (Asamblea Nacional del Ecuador, 2019) corresponden a: cigarrillos, productos del tabaco y sucedáneos, así también, perfumes, aguas de tocador o similares, juegos de video, armas de fuego, municiones y armas deportivas, a más de, vehículos de transporte terrestre incluye a híbridos y eléctricos, focos incandescentes, helicópteros, motos acuáticas, barcos, mencionado también las bebidas alcohólicas, ya sea cerveza industrial como la artesanal y bebidas energizantes como bebidas gaseosas con alto y bajo contenido de azúcar.

La base imponible del ICE está establecida en la Ley de Régimen Tributario, todos los sujetos pasivos están en las obligaciones de pagar este impuesto, que se grava considerando el precio ex fábrica y ex aduana, estos incluirán su deducibilidad según corresponda para la renta, menos el IVA y el ICE, entre ellos se establece el costo de producción de bienes, los valores recaudados por aduana en fondos, bienes y tasas, además los rubros que constituyan gastos y costos totales, así como gastos de almacenamiento, venta, administrativos y de trasporte necesario para el importador. Los autores (Delgadillo \& Calderón, 2014) mencionan que este impuesto se grava a las ventas de algunas mercaderías con excepción de ciertos productos importados y se aplica desgravamen del bien por medio de un impuesto específico a través del consumo de bienes adquiridos por la sociedad, es decir, los productos de gastos menos necesarios que son las bases razonables del impuesto. El cálculo del ICE se lo presenta de diferentes formas, de manera específica se grava con una tarifa fija a cada unidad sin importar su valor, el impuesto de valores se aplica mediante una tarifa porcentual sobre el precio de venta al público o en los precios referenciales que establece el Servicio de Rentas Internas como en vehículos; y de manera mixta esta relación combinada con los dos tipos de imposición donde se establece grabar un valor específico con respecto al grado alcohólico, más una tarifa porcentual con respecto al costo de venta. (Peláez-Fernández \& Gutiérrez-Jaramillo, 2016). 
En el siguiente esquema gráfico, se observa el historial de la recaudación del ICE a partir del año 2010 hasta el año 2019, como se relacionan de un año a otro, la recaudación tributaria del ICE y el crecimiento del presupuesto general del Estado, información tomada del Servicio de Rentas Internas de los periodos estudiados (Ver figura 1).

\section{Recaudación de ICE 2010-2019}

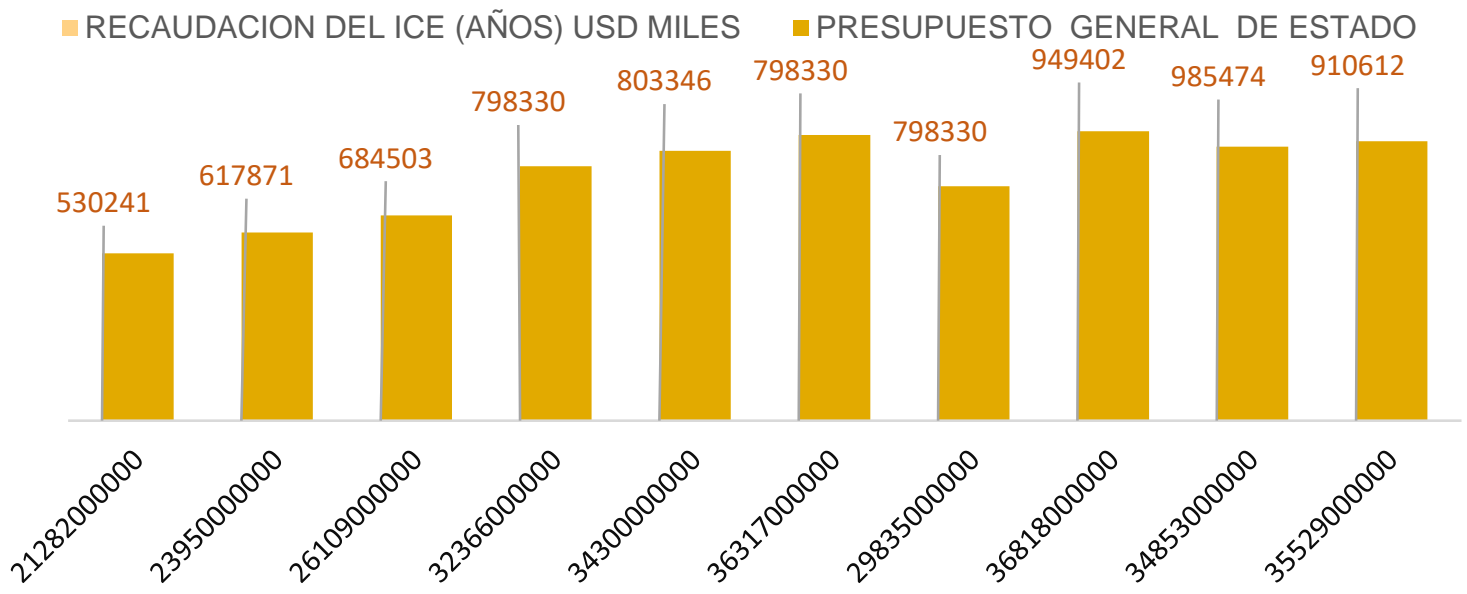

Figura 1. Recaudación del ICE desde el año 2010-2019 en relación con el presupuesto general del Estado.

Fuente: Servicio de Rentas internas (2020).

De manera general, desde el año 2010 hasta el 2019 el presupuesto general del Estado ha ido en crecimiento según la proforma presupuestaria del país, sin embargo, la evasión del ICE se efectúa por medio del valor bruto de producción junto con las importaciones; la base imponible por concepto de elaboración parte del valor bruto, donde se efectúa las exenciones establecidas por la ley. En conclusión, el ICE desde varias perspectivas de estudio se encuentra inmerso en el ámbito nacional e internacional, ya que está presente en los productos nacionales e importados, este impuesto no solo tiene esencia recaudatoria, sino que, permite regular el consumo de productos nocivos tales como el tabaco y el cigarrillo. 


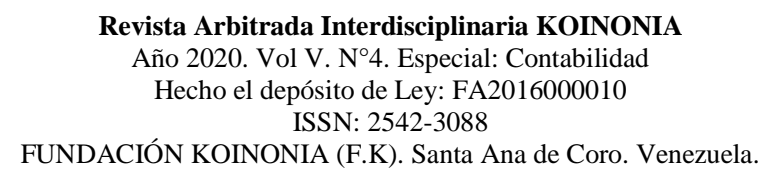

Jessica Alexandra Allauca-Llamuca; Rolando Patricio Andrade-Amoroso; Pedro Yamil Astudillo-Arias

Según él (Ministerio de Economía y Finanzas, 2018), la recaudación total ascendió a 935.04 millones, en el año 2017 donde se logró la recaudación en el consolidado Nacional de 949402 miles de dólares americanos destinados en el presupuesto anual, con un incremento del 17,76\% registrado al año anterior, esto se explica por la aplicación del sistema de desmantelamiento arancelario sobre tasas temporales. Además, se agravó con nuevos impuestos a los bienes y servicios relacionados con la telefonía fija, planes de celulares con una tarifa ad valorem del 15\%; bebidas gaseosas y no alcohólicas menor o igual a 25 gramos se graba una tarifa ad valoren del 10\%.

En el año 2018 la recaudación fue de 985, 474 miles de dólares americanos, teniendo un incremento $10.79 \%$ mayor a la registrada del año anterior, por medio de los datos representados en este año, su incremento se debió a operaciones de mercado interno, demanda de bienes importados por la reducción de las salvaguardias y tasas arancelarias, esta base se determina sobre el precio de venta al público previsto por el fabricante o su vez el importador donde se deberá restar el IVA y el ICE con base a los precios establecidos emitidos por el Servicio de Rentas Internas.

Por consiguiente, el análisis realizado al período mencionado, determina que la recaudación del ICE según la (Asamblea Nacional del Ecuador, 2016) aumentó, debido al incremento de la tarifa por unidad de cigarrillo de 0,13 a 0,16 ctvs.; bebidas alcohólicas, como la cerveza en que se estableció una tarifa definida sobre el total en litros de alcohol puro, de USD 12 en la cerveza industrial y USD 7,24 en la cerveza artesanal. Así mismo, el precio ex aduana o ex fábrica superó los 4,28 dólares americanos, por cuanto se aplicó una tasa ad valorem del $75 \%$, los servicios de telefonía y planes móviles presentaron una tarifa ad valorem del 15\%; también en el caso de bebidas gaseosas y energizantes con contenido de azúcar menor o igual a 25 gramos por litro se estableció una tarifa ad valorem del $10 \%$.

Para el año 2019 la recaudación disminuyó a 910,612 miles de dólares americanos con relación al año pasado, esta cifra se determina por medio de la (Asamblea Nacional República del Ecuador, 2019) que señala nuevos rubros en la obtención de impuestos, 
tales como; planes personales de teléfono móvil, plataformas digitales (Netflix; Uber), fundas plásticas y una contribución especial de empresas importadoras durante tres años. De tal manera que, los demás rubros señalados por la ley se quedaron establecidos y por ningún motivo serán suprimidos en los fines correspondientes en la obtención de los recursos económicos provistos al Estado.

Entre los productos que se ha determinado mayor evasión fiscal están el gas, telas, combustible, bebidas alcohólicas, cigarrillo, aparatos electrónicos, entre otros, por lo tanto, por medio del contrabando se pierden hasta 700 millones de dólares en el año, en consecuencia, se ve afectado el sector productivo nacional, principalmente la industria de artículos artesanales, bebidas artesanales, entre otros, lo que ocasiona la disminución de fuentes de empleo y el perjuicio económico al país.

En función de lo planteado, la investigación tuvo por objetivo analizar los efectos económicos en el sector empresarial del Ecuador por las reformas tributarias en el ICE del Ecuador.

\section{MÉTODO}

La presente investigación fue de tipo no experimental debido a que no se manipuló las variables de estudio, tuvo un alcance descriptivo puesto que se narró la incidencia que tuvo la recaudación del impuesto a los consumos especiales durante los tres períodos analizados con base en información real. En cuanto al diseño, este fue transversal por cuanto la información se levantó en un solo momento del tiempo considerando los períodos del 2017 al 2019 y tuvo como finalidad establecer la incidencia del ICE en el presupuesto general del Estado.

El tipo de muestreo fue por conveniencia en medida de la restricción de la emergencia sanitaria, considerando criterios para la selección de la muestra como proximidad al lugar, conocimiento de la gestión y la facilidad de traslado; en consecuencia, se contó con la participación de 25 empresas y sus respectivos gestores tributarios, a quienes se les aplicó encuesta y cuestionario de varia alternativas de respuestas, analizándose la 
información recopilada a partir de análisis de contenido documental y estadística descriptiva.

\section{RESULTADOS}

\section{Representación del impuesto a los consumos especiales}

El impuesto a los consumos especiales desde su creación es aplicable a bienes y servicios nacionales e importados según la Ley de Régimen Tributario Interno Art. 82, su recaudación se destina al desarrollo económico nacional, al respecto, el $88 \%$ de los consultados manifiestan que las medidas establecidas por la Administración Tributaria y el Gobierno Nacional para la recaudación del tributo fueron útiles y necesarias para la estabilidad económica del país, con base en las proyecciones de presupuesto general del Estado, por cuanto han generado más ingresos que contribuyen a los ecuatorianos; mientras que, el $12 \%$ restante de los encuestados señalan que las medidas adoptadas han dado pasó a un mayor índice de elusión y evasión tributaria por parte de los contribuyentes, elevándose cada año la falta de cultura tributaria.

\section{Sistema de recaudación tributaria}

El Servicio de Rentas Internas tiene por finalidad gestionar la política tributaria, asegurando la recaudación destinada a financiar la prestación de bienes y servicios públicos, el gasto social y otras actividades que se destinen al progreso nacional, por consiguiente, la recaudación del ICE juega un rol fundamental en las finanzas nacionales, sin embargo, esta carga económica se traslada al consumidor final, en este sentido, el $83 \%$ de los encuestados afirman que las reformas tributarias propuestas en el año 2019 han elevado de forma significativa sus precios de venta al público, en tanto que, el 17\% señalan no haber tenido mayor afectación en sus precios de venta. 


\section{Reforma tributaria relacionada con el ICE}

Al consultar a los empresarios su apreciación sobre las reformas tributarias al ICE establecidas en la Ley de Simplificación y Progresividad Tributaria, el $76 \%$ de encuestados mencionaron estar de acuerdo con los nuevos productos que se incluyeron en este impuesto así como con los valores y porcentajes establecidos, por su parte, el $24 \%$ restante, cuestionan esta nueva ley y consideran que se deberían eliminar ciertos productos que graban dicho impuesto, ya que afirman que la economía ecuatoriana no soporta una mayor carga impositiva.

\section{Incremento de costos de producción}

Al consultarles a los empresarios si creen que la reforma tributaria con respecto al ICE ha incrementado los costos de producción de las bebidas alcohólicas, el $82 \%$ de encuestado respondieron que sí, aduciendo, además, que esta reforma ha frenado el crecimiento económico de las pequeñas empresas fabricantes de este tipo de productos, puesto que la demanda se ha contraído.

\section{Capital de trabajo}

El capital de trabajo lo constituyen los recursos financieros con los que cuenta una empresa para la ejecución de sus operaciones, referente a este tema, el 90\% de encuestados señalaron que la reforma tributaria impactó en una escala media a su capital de trabajo, puesto que existe una menor rotación de los inventarios, tan solo el 10\% restante, señalan que su capital de trabajo tuvo un bajo impacto.

\section{Costos de materias primas}

Al analizar los efectos que provocan en el sector empresarial las reformas tributarias, el 95\% de consultados manifestaron que las reformas del ICE a más de afectar a los productores finales, también están perjudicando en gran medida a los productores de materias primas por formar parte de la cadena de valor, de forma principal en aquellos 
productos que graban doble impuesto como las bebidas gaseosas, al respecto, se evidencio que las compañías que comercializan este tipo de productos están realizando ajustes comerciales con sus clientes, ya que consideran que la afectación es muy alta al afirmar que las modificaciones del ICE e IVA están generando un espiral de costo que disminuye su liquidez.

\section{Utilidades}

Las utilidades representan las ganancias que las empresas obtienen al término de un ejercicio contable. Al consultarles a los empresarios si durante el primer trimestre del año 2020 se han visto afectados sus resultados económicos a consecuencia del incremento del ICE, el 75\% respondió que sus resultados han tenido un alto nivel de afectación, el $15 \%$ respondió que su nivel de afectación con relación a los resultados fue medio, y el $10 \%$ señaló que sus niveles de rentabilidad se afectaron en un nivel bajo durante el primer trimestre del año.

\section{Conocimiento y cumplimiento de las obligaciones tributarias}

La obligación tributaria apela al compromiso de índole jurídico-fiscal de personas naturales y jurídicas hacia el pago de impuestos, así como de sus requerimientos formales. En este contexto, el $76 \%$ de los encuestados indicaron desconocer todas las reformas tributarias implantadas o modificadas a partir del año 2020 relacionadas con el ICE, argumentan, además, que no existe una mayor cobertura informativa a nivel nacional con directrices adecuadas que permitan el oportuno cumplimiento de las obligaciones con el fisco.

\section{Evasión en el pago del ICE}

La evasión tributaria denominada también como fraude fiscal o conducta ilícita por parte de los contribuyentes o empresas de manera dolosa o culposa tiene lugar cuando el contribuyente oculta u omite información de ingresos y bienes a la administración 
tributaria. Al consultarles a los empresarios que efectos negativos provocarán en la economía del país las reformas tributarias establecidas en la Ley de Simplificación y Progresividad Tributaria, el $86 \%$ de encuestados manifestaron que esto conllevará a una mayor evasión y elusión tributaria sustentada en los vacíos legales, mientras que, el otro $14 \%$ afirman que estas nuevas medidas incentivaran al contrabando de productos.

\section{PROPUESTA}

De acuerdo a los resultados obtenidos de la presente investigación, se evidencia el problema a destacar en evasión del ICE en la recaudación tributaria por parte de la administración, por lo que se propone diseñar estrategias tributarias para el mejoramiento de la recaudación en el sector productivo-comercial como mecanismo preventivo ante la evasión tributaria.

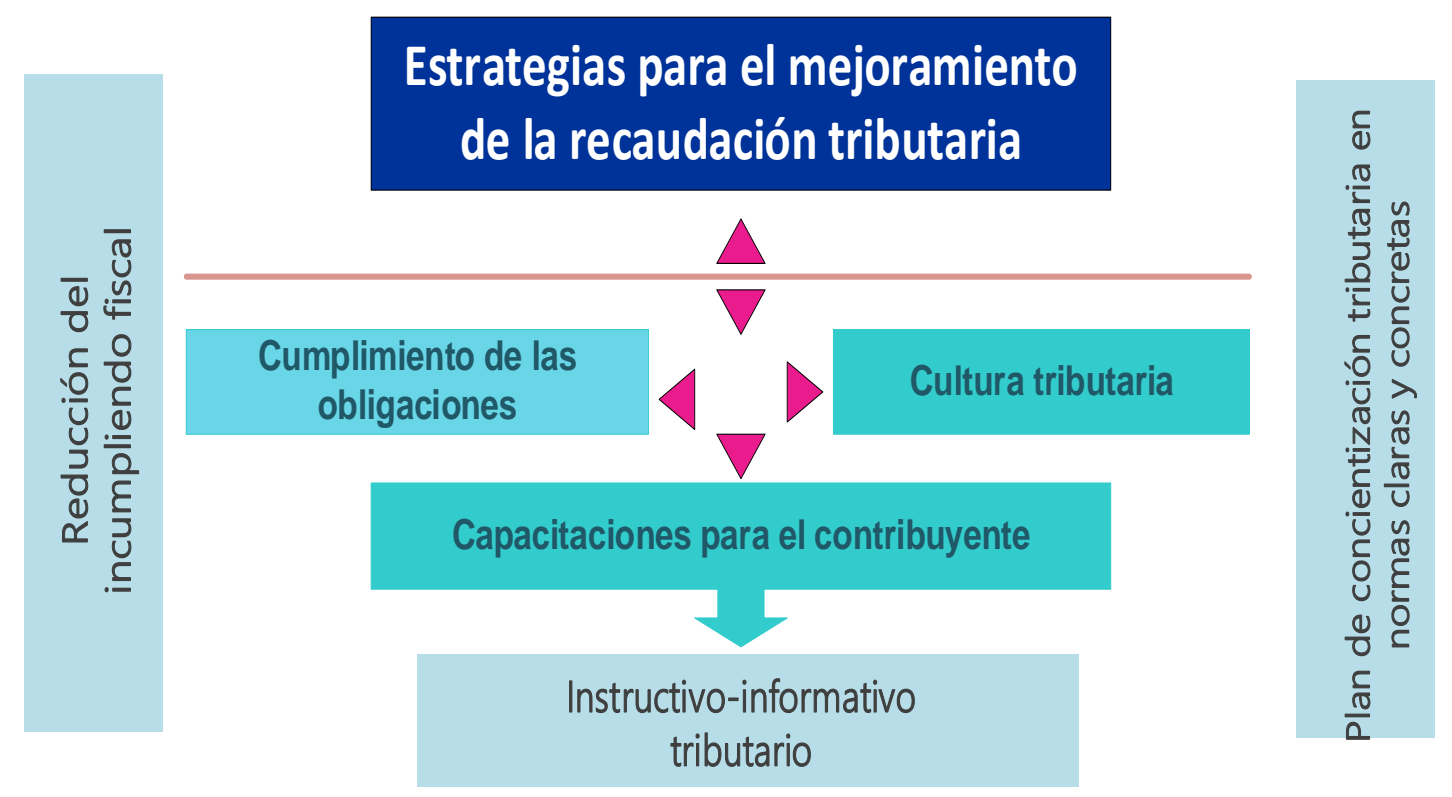

Figura 4. Estrategias para el mejoramiento de la recaudación tributaria. 


\section{Sustento normativo:}

En la elaboración del diseño de estrategias para el mejoramiento de la recaudación tributaria se sustenta en la base legal vigente en Ecuador, por consiguiente, el proceso de elaboración se fundamenta en la Ley Orgánica para el Equilibrio de las Finanzas Públicas y Reglamento para la Aplicación Ley Orgánica de Régimen Tributario Interno.

\section{Información de cumplimiento:}

Todos los representantes legales deben adjuntar la siguiente información para el cumplimiento de la obligación:

Declaración de ICE mensual: para la declaración mensual del ICE por actividades u operaciones económicas gravadas con este impuesto se realizará la declaración según su noveno dígito del régimen único de contribuyente (RUC), a través del formulario de declaración del impuesto a los consumos especiales mediante la página web institucional proporcionada por el SRI.

Anexo del ICE mensual: la presentación de anexo mensual del ICE se debe instalar en el Sistema de Declaración de Información en Medio Magnético (DIMM) la última versión del anexo ICE, solicitar por medio del correo electrónico la creación de códigos de productos tales como; grado alcohólico, marca, presentación, clasificación, capacidad y unidad, además se adjuntará los escaneados de registros sanitarios, notificación sanitaria, buenas practicas manufactureras en los productos que lo soliciten. Se revisará las fichas técnicas correspondientes y se codificará dependiendo el bien o servicio grabado con el ICE, se generará el archivo en XML y se enviará como archivo comprimido zip a través de la página web del SRI. 
Anexo del precio venta al público (PVP): Este anexo se presentará en los primeros cinco días del mes de enero de cada año proporcionando una información de todos los productos o servicios que estén sujetos a este impuesto, no obstante, es importante realizar una variación en la información de los precios cada vez que sea necesario; no se enviara la declaración en cero al no tener movimiento en el periodo, en su defecto el contribuyente presentará un trámite simple con una solicitud respectiva de justificación.

\section{Esquema del código ICE para la elaboración de anexos}

Según la LORTI para la elaboración de los anexos mensuales que deben ser presentadas por el contribuyente importador o nacional del impuesto a los consumos especiales y precio venta al público es necesario la tabla conformado por treinta y dos caracteres numéricos cada una con la descripción de bien o servicio y se representa de la siguiente manera (ver tabla 1).

\section{Tabla 1.}

Códigos del ICE para la elaboración de los anexos mensuales.

\begin{tabular}{|c|c|c|c|c|c|c|}
\hline $\begin{array}{l}\text { Código } \\
\text { Impuesto }\end{array}$ & $\begin{array}{l}\text { Código } \\
\text { Clasificación }\end{array}$ & $\begin{array}{l}\text { Código } \\
\text { Presentación }\end{array}$ & $\begin{array}{l}\text { Código } \\
\text { Capacidad }\end{array}$ & $\begin{array}{l}\text { Código } \\
\text { Unidad }\end{array}$ & $\begin{array}{l}\text { Código } \\
\text { País }\end{array}$ & $\begin{array}{l}\text { Código } \\
\text { Grado } \\
\text { Alcohólico }\end{array}$ \\
\hline 4 caracteres & 2 caracteres & 3 caracteres & 6 caracteres & 2 caracteres & 3 caracteres & 6 caracteres \\
\hline 3031 & 18 & 13 & 350 & 66 & 593 & 54 \\
\hline $\begin{array}{l}\text { ICE bebidas } \\
\text { alcohólicas }\end{array}$ & Whisky & $\begin{array}{l}\text { Botellas de } \\
\text { vidrio }\end{array}$ & 350 & ML & Ecuador & 18 grados \\
\hline
\end{tabular}

\section{Análisis de las fortalezas, oportunidades, debilidades y amenazas FODA, para la recaudación del ICE}

Se realiza el análisis FODA, que permite evidenciar las debilidades y amenazas para la recaudación de los impuestos que efectúa la administración y así reorientar hacia la innovación de estrategias para mejorar la recaudación tributaria de los impuestos (ver tabla 2). 
Tabla 2.

Análisis FODA.

\section{Fortalezas}

F1 Desarrollo económico del país.

F2 Departamento administrativo.

F3 Ingresos autónomos a las arcas del Estado.

F4 Contribuyentes responsables con las obligaciones.

F5 Tarifa fija.

F6 Beneficios tributarios.

F7 Exenciones.

F8

Estricto control por parte de la administración.

\section{Debilidades}

Incumplimiento del pago de obligaciones.

D2 Sistema inadecuado para el control administrativo.

Aumento de empresas para el control administrativo.

Personal no capacitado para atención al cliente.

D5 Colapso de sistema en línea.

D6

Desinformación por parte de la administración hacia los contribuyentes.

D7 Cultura tributaria con valores no éticos.

Incremento de incertidumbre por parte de los contribuyentes para grabar la obligación tributaria por parte de la administración.

D9

Actualización de tecnología a diario.

D10 Limitadas capacitaciones en temas tributarios a los contribuyentes. 
Capacitaciones oportunas a los

01 contribuyentes por medio de A1 redes sociales.

Habilitar espacios de inquietud

02 en redes sociales a los $\mathbf{A 2}$ contribuyentes.

O3 Acceso tecnológico para actualizaciones.

Crear conciencia a los contribuyentes sobre

Acceso libre a información sobre 05 sus declaraciones en línea por parte de la administración

\section{$\mathbf{0 4}$ recaudación tributaria a través de información real y oportuna.}

Aprovechar la credibilidad de la administración tributaria, para tratar de erradicar la información falsa sobre el destino de los impuestos.

Evasión de impuesto por parte del contribuyente.

Información económica errónea A3 sobre el Estado económico por parte de los contribuyentes.

\section{Estrategias para mejorar la recaudación tributaria del impuesto al ICE}

Las estrategias tributarias para la recaudación tributaria es una herramienta que facilita la aplicación de las exoneraciones tributarias conforme a la ley, así como la optimización de la carga fiscal hacia el Estado, que muchas de las veces trasgreden la norma por la falta de conocimiento y la mala aplicación o interpretación de la ley. Para la elaboración de las estrategias en mejora de la recaudación tributaria al Estado se determinó las debilidades por parte de la administración tributaria en consecuencia la implementación de oportunidades y fortalezas de las mismas donde tiene como propósito el mejorar la recaudación de los tributos y el cumplimento de las obligaciones a través de un medio de verificación en torno a la sociedad. 


\section{Estrategia1 D704: Fomentar la cultura tributaria de los contribuyentes}

Objetivo: Incentivar a la población al cumplimiento de las obligaciones tributarias Actividades:

1. Establecer normas tributarias claras, concretas y libres evitando la desinformación de los contribuyentes.

2. Instalar un mecanismo de detección de los ilícitos tributarios y aduaneros.

3. Explorar y establecer políticas de comunicación externa con base en las reformas tributarias actuales

4. Proporcionar información real sobre los recursos económicos del Estado y como están distribuidos.

5. Generar convenios entre el SRI, Colegios y universidades para capacitar a los individuos acerca del sistema tributario y sus funciones.

6. Diseñar campañas publicitarias dirigidas a la población escolar mediante historietas en las que se exponga de forma gráfica los beneficios de la sociedad ante el pago oportuno de los tributos.

7. Presentar mediante campañas publicitarias a la ciudadanía los valores recaudados anualmente por el SRI, y por consiguiente, la utilización de estos aportes.

8. Presentar mediante campañas publicitarias las consecuencias negativas que acarrea el incumplimiento de las obligaciones tributarias, de manera particular las actividades delictivas como la evasión y el contrabando.

9. Comunicar de forma permanente a los contribuyentes ya sea a través del correo electrónico, mensajes de texto o llamadas telefónicas sobre sus obligaciones de acuerdo al régimen tributario inscrito.

10. Socializar a través de plataformas digitales y redes sociales las sanciones establecidas según la normativa a consecuencia de la infracción tributaria. 


\section{Estrategia2 D401: Capacitaciones con base en planes programados con el cumplimiento tributario}

Objetivo: Capacitar a los contribuyentes en temas tributarios y elaboraciones de declaraciones.

Actividades:

1. Desarrollar capacitaciones formativas tributarias a través de redes sociales.

2. Habilitar espacios entre capacitador y contribuyente a través de plataformas digitales.

3. Ejecutar programas de instrucciones para declaraciones oportunas.

\section{Estrategia3 D102: Concientización a los contribuyentes mediante operaciones de fiscalización}

Objetivo: Incentivar a los contribuyentes al cumplimiento de las obligaciones a partir de acciones de inducción, orientación, detección de inconsistencias y ejecución de sanciones.

Actividades:

1. Incentivar a la declaración oportuna de cumplimento a través de información clara y concisa para el sustento declaratorio del impuesto.

2. Diseñar programas de fiscalización selectiva y masiva de acuerdo con los niveles de riesgo y presunción de fraude.

3. Aplicar sanciones ejemplares a los contribuyentes en casos de fraude o delitos tributarios.

4. Incentivar la formalidad de los productores que se encuentran al margen de la ley. 


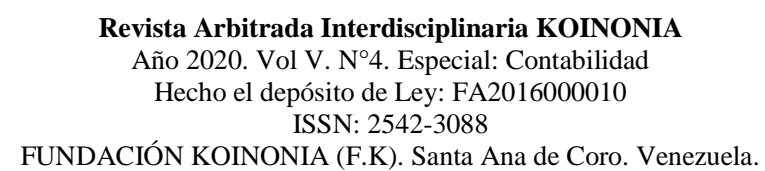

Jessica Alexandra Allauca-Llamuca; Rolando Patricio Andrade-Amoroso; Pedro Yamil Astudillo-Arias

\section{CONCLUSIÓN}

La recaudación del ICE es un impuesto significativo en el presupuesto anual de Estado, su importancia recae desde los últimos años lo que permite el cumplimiento de obligaciones y derechos del contribuyente en medida de sus actividades económicas para el beneficio de la sociedad.

Por lo tanto, la recaudación de los impuestos por parte de la administración como destino primordial es el presupuesto general del Estado en donde se representa una parte significativa del total de ingresos que se destinan para financiar servicios y obras de carácter social.

El presupuesto sustenta programas de cumplimiento con objetivos planteados de los ingresos y egresos del Estado, el mismo refleja los porcentajes de contribución de cada impuesto con su ejecución, a su vez, la ejecución presupuestaria se motiva a través de proyecciones anuales con base en el crecimiento económico del país, es decir, mediante resultados e informes anuales por periodos analizados de forma económica y estadística del recudo de los tributos.

La recaudación del ICE, así como otros impuestos tienen una incidencia directa con el presupuesto anual del Estado, ya que su recaudación determina los ingresos y el sustento de servicios, obras, gasto público, entre otros; a su vez es necesario incluir el principio de progresividad, puesto que en la medida que crece la capacidad económica del contribuyente mayor debe ser su aportación de tributos en beneficio colectivo de un país. Conforme a los resultados obtenidos en la fase de diagnóstico, se evidencia la afectación que perciben los empresarios por la nueva Ley de Simplificación y Progresividad Tributaria, que a más de incluir nuevos productos y servicios en su determinación ha incrementado el porcentaje en los productos que ya gravan este impuesto, por lo que, el precio de venta de los bienes y servicios se ha incrementado incidiendo en las ventas, rotación de inventarios, liquidez y utilidades de las empresas.

La aprobación de esta nueva ley tributaria ha generado un efecto en cadena entre los productores intermedios (materias primas) y los productores finales, por cuanto la 
reducción de las ventas ha traído consigo la disminución de los inventarios de materias primas, por consiguiente, los empresarios han tenido que reducir las compras de insumos necesarios para la producción.

Se proponen una serie de estrategias que los empresarios pueden adoptar con la finalidad de optimizar su pago de impuestos y cumplir a tiempo con sus obligaciones tributarias, las mismas se amparan en la determinación anticipada de los impuestos a efectos de la aprobación de la nueva ley tributaria en el Ecuador, de tal manera que se pueda realizar un planeamiento que considere las alternativas de ahorro en los impuestos por la adopción de los incentivos tributarios e incremento de la rentabilidad de los empresarios, con miras a elevar los niveles de venta, a mejorar la liquidez y el flujo de caja.

\section{FINANCIAMIENTO}

No monetario.

\section{AGRADECIMIENTO}

A la Universidad Católica de Cuenca; por el apoyo en el desarrollo de la investigación.

\section{REFERENCIAS CONSULTADAS}

Almeida-Haro, P. (2017). Control de la evasión tributaria en un país en vías de desarrollo: La visibilidad de la economía oculta y su evasión. [Control of tax evasion in a developing country: The visibility of the hidden economy and its evasion]. Tesis doctoral. Universitat de Lleida. Recuperado de https://n9.cl/v36y

Andrade-Donoso M, \& Cevallos-Caza K. (2020). Cultura tributaria en el Ecuador y sostenibilidad fiscal. [Tax culture in Ecuador and fiscal sustainability]. Eruditus, $1(1) ; 49-62$.

Asamblea Nacional del Ecuador. (2008). Constitución de la República del Ecuador. [Costitution of the Republic of Ecuador]. Recuperado de https://cutt.ly/8pekvyK 


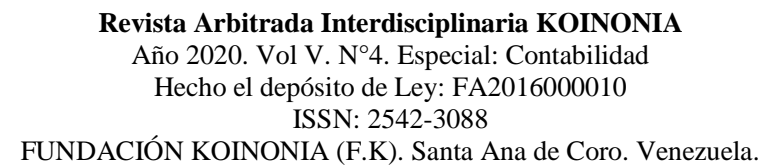

Jessica Alexandra Allauca-Llamuca; Rolando Patricio Andrade-Amoroso; Pedro Yamil Astudillo-Arias

Asamblea Nacional del Ecuador. (2016). Ley Orgánica para el Equilibrio de las Finanzas Públicas. [Organic Law for the Balance of Public Finances]. Recuperado de https://n9.cl/yfl6h

Asamblea Nacional República del Ecuador (2019). Ley de Simplificación y Progresividad Tributaria. [Tax Simplification and Progressivity Law]: Recuperado de https://n9.cl/miit

Delgadillo, M. F., \& Calderón, C. (2014). Estimación de la evasión en el impuesto al consumo especifico (ICE) 1988-1992. [Estimation of evasion in the specific consumption tax (ICE) 1988-1992]. Recuperado de https://n9.cl/h2qd

El Telégrafo. (6 de junio de 2020). Ecuador pierde entre $\$ 300$ y $\$ 400$ millones anuales por evasión fiscal. [Ecuador loses between $\$ 300$ and $\$ 400$ million annually due to tax evasion]. Recuperado de https://n9.cl/603fn

Huerta-González, A. (2015). La austeridad fiscal recrudece los problemas de la economía economía. [ Fiscal austerity escalates the problems of the economy]. El Cotidiano, (192), 44-57.

Illescas-Guillén, L., Narváez-Zurita, C., \& Erazo-Álvarez, J. (2020). Procesos de convergencia a Normas Internacionales de Contabilidad del Sector Público. [Convergence processes to International Public Sector Accounting Standards]. Revista Arbitrada Interdisciplinaria Koinonía, 5(10), 92-125. http://dx.doi.org/10.35381/r.k.v5i10.690

Llivicura-Ávila, H., Erazo-Álvarez, J., \& Narváez-Zurita, C. (2019). Criterios de asignación de gastos para el soporte técnico en la industria manufacturera de línea blanca. [Expense allocation criteria for technical support in the white goods manufacturing industry]. Revista Arbitrada Interdisciplinaria Koinonía, 4(1), 153-179. http://dx.doi.org/10.35381/r.k.v4i1.376

Mantilla-Falcón, L. (2017). La política fiscal y recaudación de impuestos: a los consumos especiales y salida de divisas en la zona 3 durante el periodo $2013-2015$. [Fiscal policy and tax collection: special consumption and outflow of foreign currency in zone 3 during the period 2013 - 2015]. Augusto Guzzo Revista AcadêMica, 1(20), 13-22.

Ministerio de Economía y Finanzas (2019). Presupuesto General del Estado Enero - junio 2019. [General State Budget January - June 2019]. Recuperado de https://n9.cl/3rbgo 


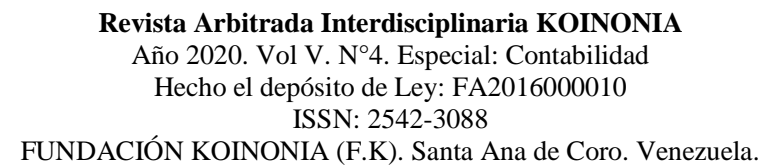

Jessica Alexandra Allauca-Llamuca; Rolando Patricio Andrade-Amoroso; Pedro Yamil Astudillo-Arias

Ministerio de Economía y Finanzas. (2018). Informe de Ejecución Presupuestaria 2017. [Budget Execution Report 2017]. Recuperado de https://n9.cl/nxc4

Peláez-Fernández, M, \& Gutiérrez-Jaramillo, N. (2016). Los tributos y su aporte al presupuesto general del Estado, un análisis comparativo en la República del Ecuador: períodos 2013-2014-2015. [The taxes and their contribution to the general budget of the state, a comparative analysis in the Republic of Ecuado]. [Internet] El observatorio de la Economía Latinoamerica. Recuperado de https://cutt.ly/Npeae3l

Saeteros-Molina, A., Narváez-Zurita, C., \& Erazo-Álvarez, J. (2020). La contabilidad gubernamental como herramienta de gestión de las instituciones públicas no financieras. [Government accounting as a management tool for non-financial public institutions]. Revista Arbitrada Interdisciplinaria Koinonía, 5(10), 226-254.

Sánchez, J., Esparza, F., Gaibor, I., \& Barba, M. (2020). La evasión tributaria originada en el uso de comprobantes de venta. [Tax evasion caused by the use of sales receipts]. KnE Engineering, 5(2), 149-163. https://doi.org/10.18502/keg.v5i2.623

Santiana-Castillo, A. S. (2013). Medidas tendientes a combatir la elusión y la evasión fiscal de impuesto a la renta de las sociedades en el Ecuador. [Measures to combat tax avoidance and evasion of corporate income tax in Ecuador]. Tesis de maestría. Universidad Andina Simón Bolívar, Sede Ecuador. Recuperado de https://n9.cl//8w2b

Servicio de Rentas internas (2020). Estadísticas generales de recaudación. [General collection statistics]. Recuperado de https://n9.cl/i8twt

Zavala, R. (2015). El impuesto a los consumos especiales (ICE) aplicado a las bebidas alcohólicas en Ecuador, caso: cervezas (2008 - 2013). [The special consumption tax (ICE) applied to alcoholic beverages in Ecuador, case: beers (2008 - 2013)]. Recuperado de https://cutt.ly/2pemspC

C2020 por los autores. Este artículo es de acceso abierto y distribuido según los términos y condiciones de la licencia Creative Commons Atribución-NoComercial-Compartirlgual 4.0 Internacional (CC BY-NC-SA 4.0) (https://creativecommons.org/licenses/by-nc-sa/4.0/ 